\title{
Les rôles physiologiques majeurs exercés par les acides gras polyinsaturés (AGPI)
}

\author{
Philippe GUESNET ${ }^{1}$ \\ Jean-Marc ALESSANDRI ${ }^{1}$ \\ Pierre ASTORG ${ }^{2}$ \\ Fabien PIFFERI ${ }^{1}$ \\ Monique LAVIALLE ${ }^{1}$ \\ ${ }^{1}$ Groupe Neurobiologie des lipides, \\ Laboratoire de nutrition et sécurité alimentaire, \\ Institut national de la recherche agronomique \\ (INRA), CRJ, 78352 Jouy-en-Josas cedex \\ <philippe.guesnet@jouy.inra.fr> \\ 2 UMR INSERM 557/INRA/CNAM \\ "Epidémiologie nutritionnelle", ISTNA/CNAM, \\ 5 rue du Vertbois, 75003 Paris France
}

\begin{abstract}
Polyunsaturated fatty acids (PUFAs) are essential nutrients for mammals and the human species, and belong to either of two distinct and not interconvertible series, omega 6 and omega 3. The metabolic precursors of these two series, linoleic and $\alpha$-linolenic acids respectively, are the dietary essential fatty acids. These two fatty acids, once absorbed, lead to the specific synthesis and incorporation in practically all cell membranes of long-chain active PUFA derivatives such as arachidonic acid for the omega 6 series and eicosapentaenoic and docosahexaenoic acids for the omega 3 series. Long-chain PUFA affect many physiological functions because they are essential factors in many cellular functions by regulating physical properties of membranes, eicosanoid signalling and gene expression of encoding enzymes of triglyceride storage and fatty acid oxidation. The consumption of omega 6 and omega 3 fatty acids in equilibrated proportions could be crucial in the regulation of cellular physiology and in the prevention of pathologies such as cardiovascular, autoimmune and inflammatory diseases, diabetes and obesity, certain neuropsychiatric affections, etc. Indeed, the dietary intake of omega 3 fatty acid ( $\alpha$-linolenate and also docosahexaenoate) are crucial parameters in the development of retinal and neural function in the newborn infant. On the other hand, a high ratio of omega6/omega 3 fatty acids in cell membranes due to an excessive consumption of omega 6 fatty acids and a relative omega 3 fatty acid deficiency, may promote the pathogenesis of several diseases, including cardiovascular diseases, metabolic syndrome, inflammatory disorders and obesity.
\end{abstract}

Key words: arachidonic acid, docosahexaenoic acid, eicosapentaenoic acid, physiological functions, polyunsaturated fatty acids, cell membranes

composés à plus de $95 \%$ de triglycérides (ou triacylglycérols), la forme chimique associant trois (3) acides gras. Un homme adulte dont la ration alimentaire apporte 2500 kilocalories, fournies pour un tiers sous la forme de lipides, ingère quotidiennement environ $100 \mathrm{~g}$ d'acides gras [1]. Après leur absorption au niveau intestinal par les entérocytes, ces acides gras sont véhiculés dans la circulation sanguine sous la forme de lipoprotéines approvisionnant les tissus utilisateurs (tissu adipeux, muscle, foie) ; dans un second temps, ils sont métabolisés par le foie puis redistribués sous la forme de lipoprotéines plus denses dans l'ensemble de l'organisme. Par leur catabolisme, notamment par la $\beta$-oxydation mitochondriale, tous les acides gras alimentaires fournissent de l'énergie ( $1 \mathrm{~g}$ d'acides gras équivaut à 9 kilocalories, contre 4 kilocalories pour les sucres et les protéines) et la majorité présentent en commun une fonction structurale comme constituants des phospholipides des membranes cellulaires. En revanche, certains d'entre eux exercent plus spécifiquement un rôle de nutriment indispensable: ce sont les acides gras polyinsaturés (AGPI) dits « essentiels » des séries oméga 6 (ou n-6) et oméga 3 (ou n-3) dont le métabolisme conduit, d'une part à la synthèse de dérivés à longue chaîne constitutifs de toutes les membranes cellulaires (rôle structural) et, d'autre part, à la synthèse de médiateurs bioactifs sous la forme de molécules oxygénées (eicosanoïdes, docosanoïdes, etc.) (figure 1). Ces molécules ont un mode d'action apparenté à celui des hormones et régulent des fonctions physiologiques aussi fondamentales que la contraction des muscles lisses, la reproduction, la coagulation sanguine, l'inflammation, l'activité neuronale, etc. Les AGPI et leurs dérivés oxygénés régulent également de multiples voies métaboliques en modulant certains processus de signalisation intracellulaire, ainsi que l'expression de gènes cibles via l'activation spécifique de facteurs de transcription (figure 1). Ainsi, de par leur nature et leur abondance dans I'alimentation, les AGPI oméga 6 et oméga 3 sont susceptibles d'interférer sur l'étiologie d'un grand nombre de pathologies (maladies cardiovasculaires et inflammatoires, cancers, neuropathologies, etc.) [2]. L'intérêt spécifique des AGPI en oméga 3 , et tout particulièrement des AGPI en oméga 3 à longue chaîne présents en 


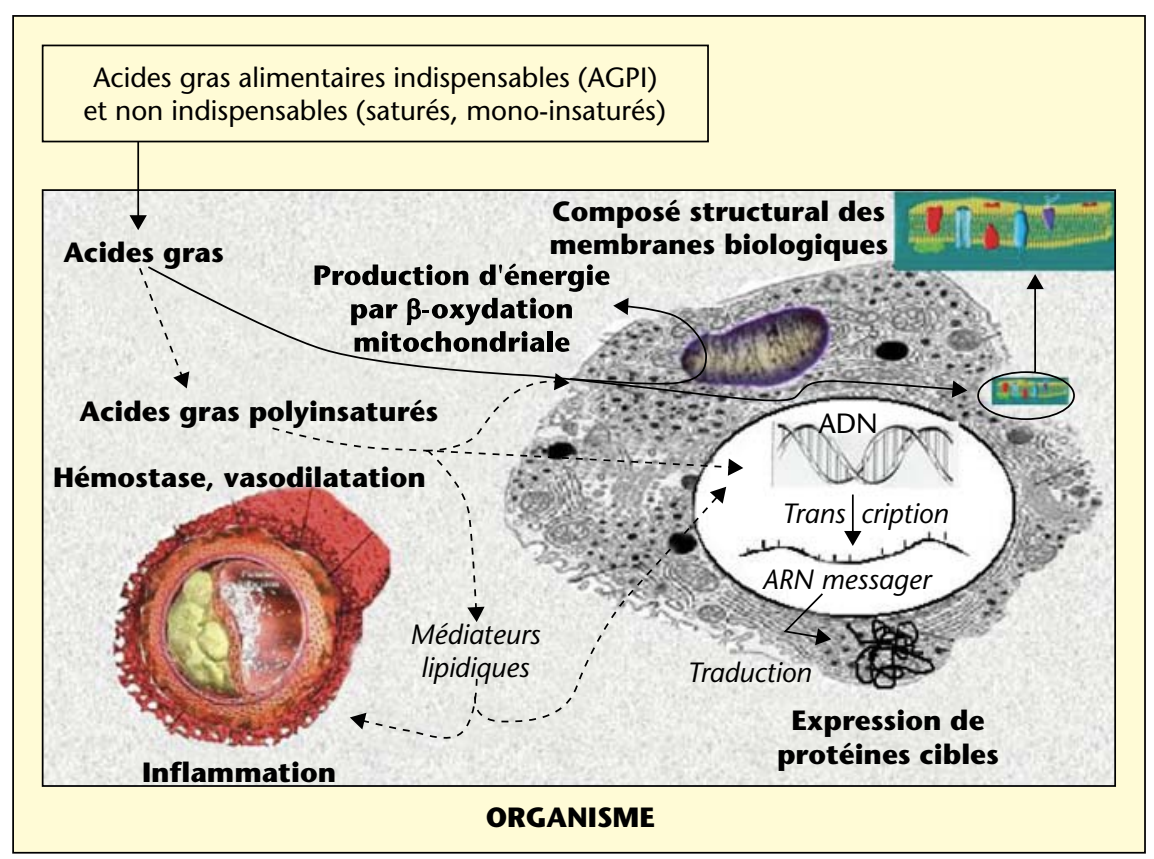

Figure 1. Principales fonctions exercées par les acides gras dans notre organisme.

abondance dans les huiles de poisson, est parfaitement établi sur le plan de la physiologie cardiovasculaire et de l'inflammation; depuis quelques années, il fait l'objet d'un nombre croissant d'investigations en ce qui concerne la prévention de certaines pathologies du système nerveux central $[3,4]$.

Après un bref historique des données expérimentales qui ont conduit à reconnaître le caractère indispensable des AGPI, nous nous attacherons à rappeler dans cet article les aspects généraux de la structure et du métabolisme des AGPI, puis nous examinerons leurs propriétés fonctionnelles et leurs effets en regard de pathologies dont la prévalence et les symptômes sont susceptibles d'être améliorés par le réajustement des proportions des familles oméga 6 et oméga 3 de l'alimentation.

\section{Historique du concept d'indispensabilité des acides gras polyinsaturés (AGPI)}

En 1929, Burr et Burr décrivent les symptômes caractéristiques d'une alimentation totalement dépourvue d'acides gras chez le rat (retard de croissance, chute de poils, dessèchement de la peau, desquamation, altérations de la reproduction, etc.), leur suggérant des propriétés $\alpha$-linolénique ne sont pas synthétisés par le

DHA : acide docosahexaénoïque (22:603) mammifère. Il est ainsi mis en évidence que ces deux acides gras sont les précurseurs métaboliques respectifs de dérivés à longue chaîne renfermant de quatre à six insaturations, notamment de l'acide arachidonique (20:4ஸ6) pour la série oméga 6 , et de l'acide docosahexaénoïque $(22: 603)$ pour la série oméga 3. En outre, on observe que les oméga 6 et oméga 3 entrent en compétition dans ces voies métaboliques et que l'acide arachidonique est plus efficace que l'acide linoléique pour corriger les symptômes d'une alimentation dépourvue d'acides gras. Les AGPI en oméga 6 apparaissent ainsi comme des constituants ubiquitaires des membranes cellulaires contrôlant leur fonctionnement et jouent un rôle actif dans la physiologie cutanée $[5,6]$. Le caractère indispensable des AGPI pour I'homme n'est admis qu'au début des années 60 , après que des symptômes décrits précédemment soient observés chez des adultes alimentés (par voie parentérale) avec des préparations alimentaires dépourvues de lipides (eczéma, lésions cutanées) et chez des nouveau-nés allaités avec des laits infantiles également dépourvus de graisse (dessèchement et épaississement de la peau, desquamation) [7]. À nouveau, l'acide linoléique est considéré comme le seul acide gras indispensable car son addition dans l'alimentation fait disparaître ces symptômes.

La possibilité que les AGPI en oméga 3 puissent également exercer un rôle physiologique spécifique, distinct de celui des AGPI en oméga 6, est envisagée seulement à partir des années 1970. II apparaît que l'acide docosahexaénoïque (DHA ou 22:603) est particulièrement abondant dans les phospholipides du système nerveux (cerveau, rétine) de tous les mammifères y compris l'homme [8] (figure 2). Dans le même temps, des observations effectuées chez les Ésquimaux groenlandais révèlent le rôle cardioprotecteur des graisses de poissons et de mammifères marins dû à leur richesse en oméga 3 à longue chaîne (en DHA et en acide

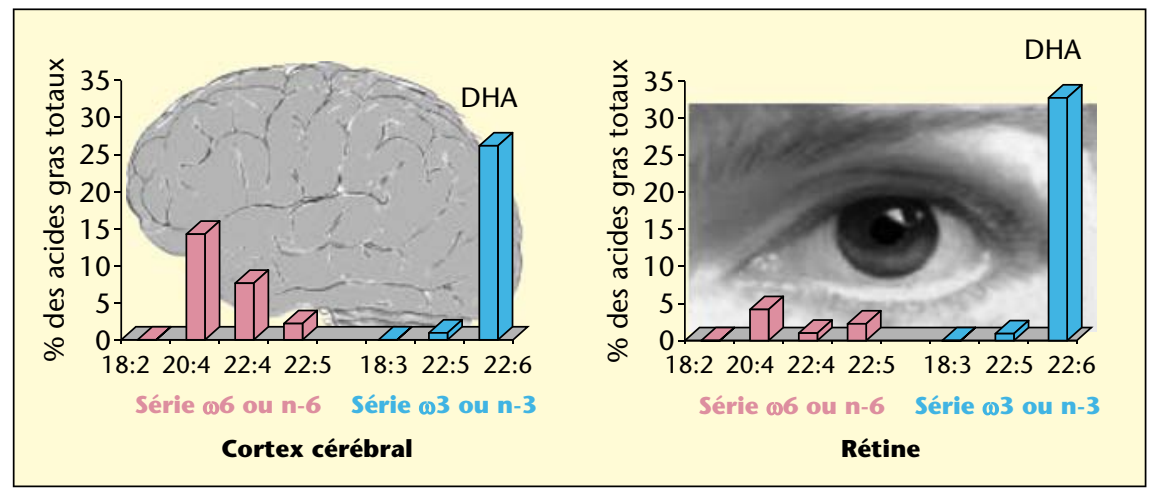

Figure 2. Teneurs des principaux acides gras polyinsaturés (AGPI) retrouvés des phospholipides des membranes du cerveau et de la rétine de l'homme : exemple de la phosphatidyléthanolamine (d'après [8]). 
eicosapentaénoïque, EPA) [9]. Un grand nombre de travaux publiés entre 1975 et 1990 montrent qu'une déficience alimentaire chronique en oméga 3 provoque des perturbations fonctionnelles des structures nerveuses dont les fonctions visuelles et cognitives chez le rongeur et le singe [10]. Par ailleurs, un cas de carence en oméga 3 est observé chez une fillette ayant été nourrie par voie entérale pendant 5 mois avec une émulsion dépourvue d'acide $\alpha$-linolénique [11]. Cette enfant présente des troubles neurologiques des systèmes sensoriel et moteur (engourdissement, faiblesse musculaire, troubles de la vision). L'introduction d'acide $\alpha$-linolénique dans la solution nutritive permet de faire disparaitre rapidement ces symptômes et de normaliser le statut plasmatique en oméga 3. Le caractère indispensable des oméga 3 pour l'homme est admis en 1985. Quelques années plus tard, il est mis en évidence chez l'enfant nouveau-né (prématuré et né à terme) que la consommation de laits infantiles trop pauvres en oméga 3 retarde le développement de la fonction visuelle comparativement aux enfants allaités au sein [12]. La découverte que les AGPI à 20 atomes de carbone en oméga 6 et oméga 3 sont les précurseurs de la synthèse des médiateurs lipidiques a également contribué à la reconnaissance du caractère indispensable des AGPI $[13,14]$.

\section{Structure et nomenclature des familles d'acides gras}

Les acides gras se composent d'une chaîne hydrocarbonée linéaire dont la longueur varie le plus souvent entre 12 et 22 atomes de carbone, et dont les extrémités sont constituées par des groupements carboxyle et méthyle (figure 3). Ils sont regroupés par familles distinctes selon le nombre de doubles liaisons éthyléniques (ou insaturations) qu'ils renferment: acides gras saturés ou AGS (aucune insaturation ou double liaison), mono-insaturés ou AGMI (une seule double liaison) et polyinsaturés ou AGPI (au moins deux doubles liaisons) (figure 3, tableau 1). Les doubles liaisons disposées le long de la chaîne hydrocarbonée des AGPI sont systématiquement distantes les unes des autres de trois atomes de carbone (structure vinyl-éther). Elles sont généralement en configuration cis, c'est-à-dire que les deux parties de la chaîne hydrocarbonée situées de part et d'autre de la double liaison sont du même côté par rapport au plan de la double liaison. Deux familles d'AGPI se distinguent par la position de la première double liaison située vers l'extrémité méthyle: la famille de l'acide linoléique ou oméga 6

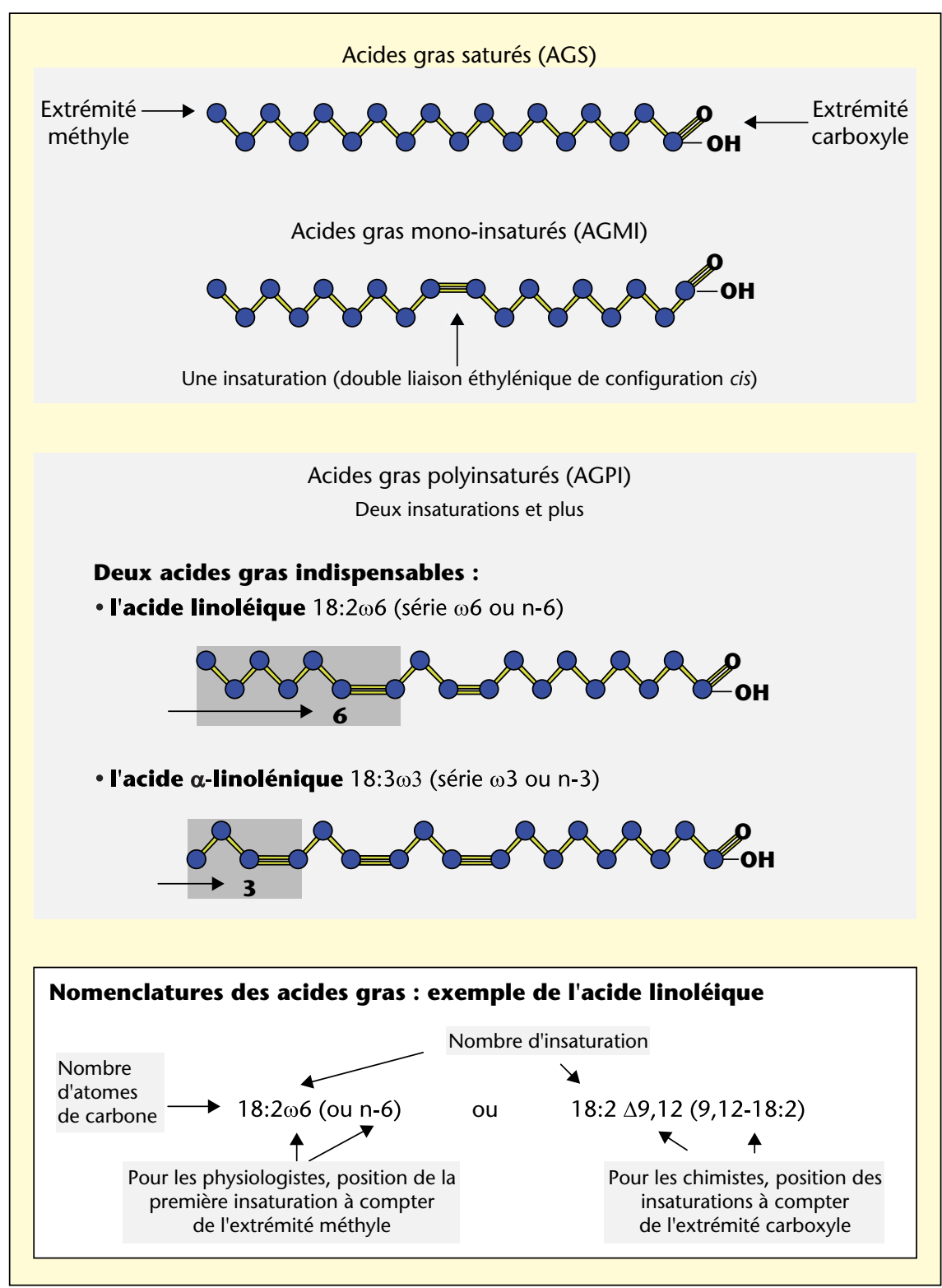

Figure 3. Structure et nomenclature des principales familles d'acides gras. Dans la représentation schématique des acides gras, la chaîne carbonée est symbolisée par une succession de sphères (atomes de carbone) reliée entre elles par des liaisons covalentes.

( $6^{\mathrm{e}}$ position en comptant à partir de l'extrémité méthyle, également dénommée $n-6)$ et celle de l'acide $\alpha$-linolénique oméga 3 ( $3^{\mathrm{e}}$ position en comptant à partir de l'extrémité méthyle, ou n-3) (figure 3). Les physiologistes caractérisent les acides gras au moyen d'une nomenclature dans laquelle apparaissent successivement le nombre d'atomes de carbone, le nombre de doubles liaisons et la position de la première double liaison numérotée à partir de l'extrémité méthyle terminale (figure 3, tableau 1). La nomenclature des chimistes se distingue de la précédente par le fait que la position des doubles liaisons est numérotée en comptant les atomes de carbone à partir de l'extrémité carboxyle (numérotation en $\Delta$ ), qui est la fonction biologiquement active de tous les acides gras. Certains acides gras polyinsaturés constituent des exceptions car ils présentent des structures particulières : présence d'une ou plusieurs doubles liaisons de configuration trans pouvant être conjuguées (formes conjuguées de l'acide linoléique ou CLA par exemple) habituellement présentes dans les corps gras hydrogénés ou de ruminants $[15,16]$, présence d'une double liaison en position $\Delta-5$ distante des autres doubles liaisons de plus de 3 atomes de carbone (huiles de conifères) [17]. 
Tableau 1. Rôles physiologiques majeurs exercés par les acides gras alimentaires chez le mammifère.

\begin{tabular}{|c|c|c|}
\hline $\begin{array}{l}\text { Acides gras } \\
\text { (appellation commune) }\end{array}$ & Formule simplifiée* & $\begin{array}{l}\text { Rôles physiologiques et/ou nutritionnels majeurs } \\
\text { (hormis comme source d'énergie) }\end{array}$ \\
\hline & Famille des acides gras saturés (ACS) & \\
\hline * Acide myristique & 14:0 & $\begin{array}{l}\text { Régule l'activité de certaines protéines membranaires en les acylant } \\
\text { Effet hypercholestérolémiant }\end{array}$ \\
\hline * Acide palmitique & $16: 0$ & Effet hypercholestérolémiant \\
\hline \multirow[t]{2}{*}{ *Acide stéarique } & $18: 0$ & $\begin{array}{l}\text { Rôle structural comme constituant des phospholipides membranaires } \\
\text { Effet neutre sur la lipémie }\end{array}$ \\
\hline & Famille des acides gras mono-insaturés (AGMI) & \\
\hline \multirow[t]{2}{*}{ *Acide oléique } & $18: 1 \omega 9$ ou n-9 $(9 c-18: 1)$ & $\begin{array}{l}\text { Rôle structural comme constituant majeur des lipides de structure } \\
\text { Propriétés éventuellement hypocholestérolémiante et antiathérogène }\end{array}$ \\
\hline & Famille des AGPI $\omega 6$ (ou n-6) & \\
\hline * Acide linoléique & $18: 2 \omega 6(9 c, 12 c-18: 2)$ & $\begin{array}{l}\text { AGPI essentiel et précurseur métabolique des AGPI en } \omega 6 \text {. Rôle structural } \\
\text { comme constituant majeur des phospholipides membranaires }\end{array}$ \\
\hline *Acide $\gamma$-linolénique (GLA) & $18: 3 \omega 6(6 c, 9 c, 12 c-18: 3)$ & Effet anti-inflammatoire \\
\hline *Acide dihomo- $\gamma$-linolénique (DGLA) & $20: 3 \omega 6(8 c, 11 c, 14 c-20: 3)$ & Précurseur des prostanoïdes de la série 1 \\
\hline * Acide arachidonique (AA) & $20: 4 \omega 6(5 c, 8 c, 11 c, 14 c-20: 4)$ & $\begin{array}{l}\text { Rôle structural comme constituant majeur des lipides de structure } \\
\text { Précurseur des prostanoïdes de la série } 2 \text { et des leucotriènes de la série 4, } \\
\text { des hydropéroxydes, des lipoxines des acides époxyeicotriénoïques, etc. }\end{array}$ \\
\hline \multirow[t]{2}{*}{ * Acide docosapentaénoïque } & $22: 5 \omega 6(4 c, 7 c, 10 c, 13 c, 16 c-22: 5)$ & $\begin{array}{l}\text { Constituant des phospholipides membranaires en situation de déficit } \\
\text { alimentaire en } \omega 3\end{array}$ \\
\hline & Famille des AGPIw3(ou n-3) & \\
\hline *Acide $\alpha$-linolénique & 18: $3 \omega 3(9 c, 12 c, 15 c-18: 3)$ & $\begin{array}{l}\text { AGPI essentiel et précurseur métabolique des AGPI en } \omega 3 \text {. Effet anti- } \\
\text { athérogène }\end{array}$ \\
\hline *Acide eicosapentaénoïque (EPA) & $20: 5 \omega 3(5 c, 8 c, 11 c, 14 c, 17 c-20: 5)$ & $\begin{array}{l}\text { Précurseur des prostanoïdes de la série } 3 \text { et des leucotriènes de la série } 5 \text {, } \\
\text { etc. Effets anti-athérogène, hypotriglycéridémiant, anti-inflammatoire, } \\
\text { etc. }\end{array}$ \\
\hline *Acide docosahexaénoïque (DHA) & $22: 6 \omega 3(4 c, 7 c, 10 c, 13 c, 16 c, 19 c-22: 6)$ & $\begin{array}{l}\text { Rôle structural comme constituant majeur des lipides de structure du } \\
\text { système nerveux central }\end{array}$ \\
\hline
\end{tabular}

* Nomenclature des chimistes qui positionnent les doubles liaisons en numérotant les atomes de carbone à partir de l'extrémité carboxyle (nomenclature en $\Delta$ ). Les doubles liaisons de géométrie cis (c) et trans ( $t$ ) apparaissent dans cette nomenclature.

\section{Le métabolisme des AGPI : les voies de bioconversion (désaturation-élongation) des dérivés à longue chaîne et de synthèse des molécules oxygénées}

Les précurseurs métaboliques respectifs des deux familles d'AGPI, I'acide linoléique (18:206) pour la famille oméga 6 et l'acide $\alpha$-linolénique $(18: 303)$ pour la famille oméga 3 , sont les acides gras dits indispensables (ou « essentiels »). En effet, les cellules de mammifères sont dans l'incapacité métabolique de les synthétiser car elles ne possèdent pas, contrairement aux cellules végétales, les désaturases permettant $d$ 'introduire des doubles liaisons à l'extrémité méthyle, à savoir les $\Delta 12$ - et $\Delta 15$ désaturases qui génèrent successivement le 18:206 et le 18:303 à partir de l'acide oléique $(18: 1 \omega 9)$. Chefs de file incontournables, ces deux acides gras conduisent, après leur absorption, à la synthèse de dérivés à longue chaîne par une succession de désaturations et d'élongations localisée dans le réticulum endoplasmique. Les doubles liaisons et atomes de carbone supplémentaires sont rajoutés vers l'extrémité carboxyle conservant ainsi la structure oméga 6 ou oméga 3 du précurseur d'origine (figure 4). Les principaux AGPI dérivés à longue chaîne ainsi formés dans les organismes animaux sont les acides dihomo- $\gamma$-linolénique $(20: 3 \omega 6)$ et arachidonique $(20: 4 \omega 6)$ pour la famille oméga 6 , et les acides eicosapentaénoïque (20:5 03 ou EPA) et docosahexaénoïque (22:603 ou DHA) pour la famille oméga 3. Ces deux familles d'AGPI ne sont pas interconvertibles mais elles entrent en compétition pour la voie de désaturation-élongation, ce qui implique un effet de «balance métabolique » entre ces deux familles. En situation d'apport alimentaire équilibré, la voie de biosynthèse des oméga 6 s'arrête à l'acide arachidonique. Elle se poursuit au-delà lorsque cet apport est déficient en oméga 3 , conduisant à la synthèse d'acide docosapentaénoïque $(22: 5 \omega 6)$ en compensation de la diminution de la synthèse du DHA. La voie de bioconversion conduisant à la synthèse des acides arachidonique et eicosapentaénoïque est localisée dans le réticulum endoplasmique de toutes les cellules de l'organisme et met en jeu l'action séquentielle de désaturases ( $\Delta 6$ et $\Delta 5$ ) et d'une élongase (figure 4). La synthèse du DHA et du 22:5 $\omega 6$ nécessite une étape terminale de $\beta$-oxydation dans les peroxysomes, raccourcissant de deux atomes de carbone leurs précurseurs respectifs à 24 atomes de carbone (produits dans le reticulum endoplasmique), le 24:603 et le 24:506 [18]. Les études métaboliques montrent que le taux de conversion de l'acide $\alpha$-linolénique en EPA et surtout en DHA est très bas chez I'homme (<1\%), suggérant que ce précurseur est une source trop limitée pour satisfaire la totalité des besoins en DHA des tissus humains [19]. Le taux de conversion serait plus élevé chez la femme que chez l'homme (effet probable du statut hormonal et des œstrogènes), ce qui permettrait de répondre à des périodes physiologiques spécifiques, notamment la grossesse et l'allaitement et aux besoins en oméga 3 du fœtus et du nouveau-né. Cette caractéristique liée au sexe résulterait également d'une moindre utilisation chez la femme des AGPI précurseurs à des fins énergétiques car les acides linoléique et $\alpha$-linolénique entrent majoritairement (> 50\%) dans la voie catabolique et sont constitutivement plus rapidement dégradées par $\beta$-oxydation que les autres acides gras à 18 atomes de carbone [20]. 


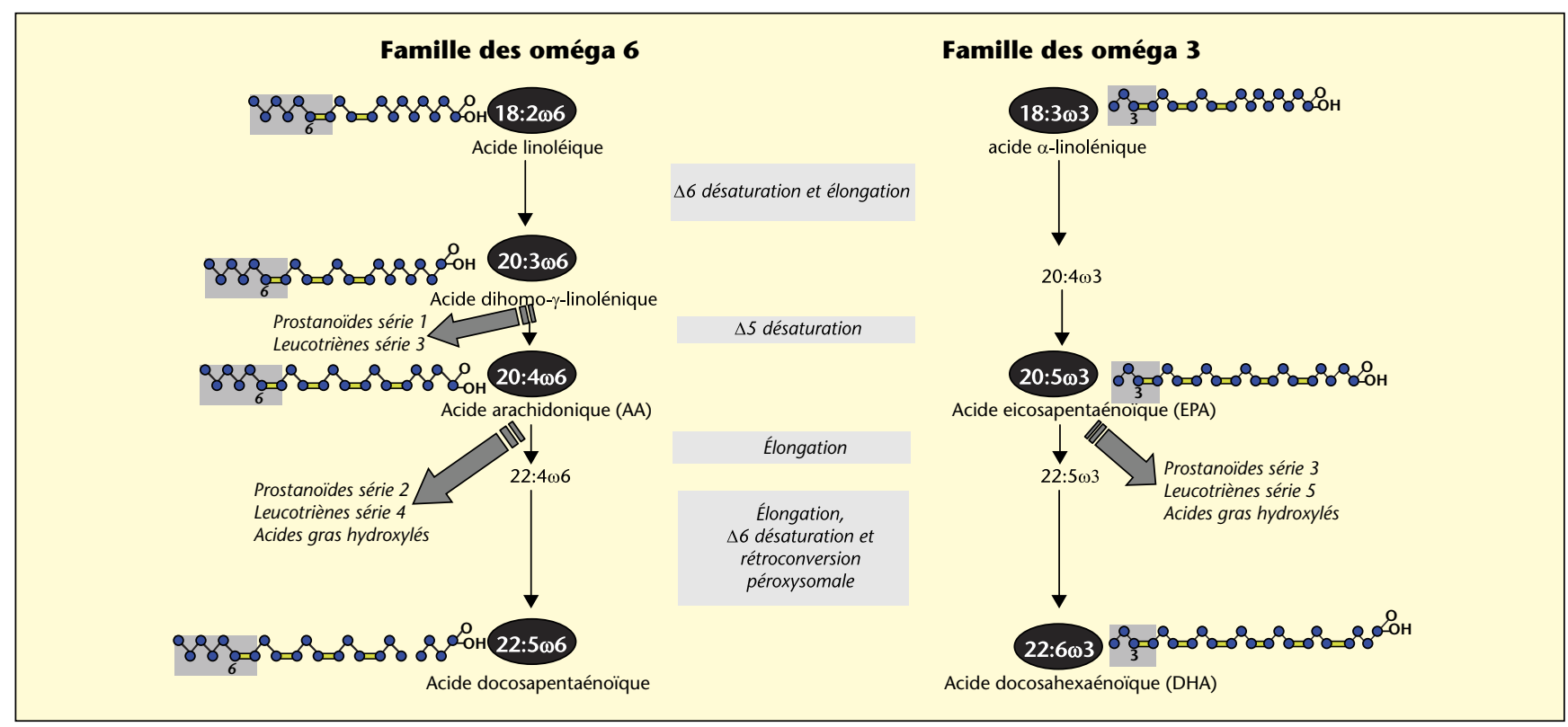

Figure 4. Voies de biosynthèse des acides gras polyinsaturés (AGPI) à longue chaîne à partir des AGPI précurseurs indispensables et de métabolisation en dérivés oxygénés dénommés eicosanoïdes (prostanoïdes, leucotriènes, AGPI hydroxylés).

Les enzymes impliquées dans la voie de biosynthèse des AGPI à longue chaine sont localisées au niveau de deux organites intracellulaires : dans le réticulum endoplasmique pour ce qui concerne les désaturases et élongases, dans les péroxysomes pour l'étape de rétroconversion du $24: 603$ en $22: 603$ par $\beta$-oxydation.

Trois des AGPI à 20 atomes de carbone formés par la voie de désaturation-élongation peuvent entrer dans les voies enzymatiques d'oxygénation, d'hydroxylation et de peroxydation conduisant à la formation de puissants médiateurs dénommés eicosanoïdes. II s'agit des acides dihomo- $\gamma$-linolénique $(20: 3 \omega 6)$ et arachidonique $(20: 406)$ pour la famille oméga 6 , et de l'acide eicosapentaénoïque $(20: 503)$ pour la famille oméga 3. Les acides arachidonique et eicosapentaénoïque sont les principaux précurseurs dans la plupart des tissus [21] (figures 4 et 5). L'action de la phospholipase A2 au niveau des phospholipides membranaires libère ces AGPI dans le cytoplasme, qui peuvent entrer dans deux voies métaboliques distinctes: la voie des cyclo-oxygénases (ou COX) générant les prostaglandines (PG), les prostacyclines (PGI) et les thromboxanes (TX), et celle des lipoxygénases (ou LOX) produisant les leucotriènes (LT) et les acides gras hydropéroxydés. On distingue trois classes de métabolites ou « séries » selon l'acide gras polyinsaturé qui en est la source: pour les prostaglandines, prostacyclines et thromboxanes, les séries 1, 2 et 3 dérivent respectivement des $20: 3 \omega 6$, $20: 4 \omega 6$ et $20: 5 \omega 3$. De même, les séries 3,4 et 5 des leucotriènes dérivent respectivement de ces trois AGPI (figure 5). Chaque tissu possède l'équipement enzymatique conduisant à la synthèse spécifique de l'une ou de l'autre de ces molécules. Ainsi à partir de l'acide arachidonique, les plaquettes synthétisent le thromboxane A2 (TXA2) grâce à l'activité thromboxane synthase, tandis que les cellules de l'endothélium vasculaire possèdent une prostaglandine synthase et une prostacycline syn-

thase leur permettant de synthétiser la prostaglandine E2 (PGE2) et la prostacycline I2 (PGI2)

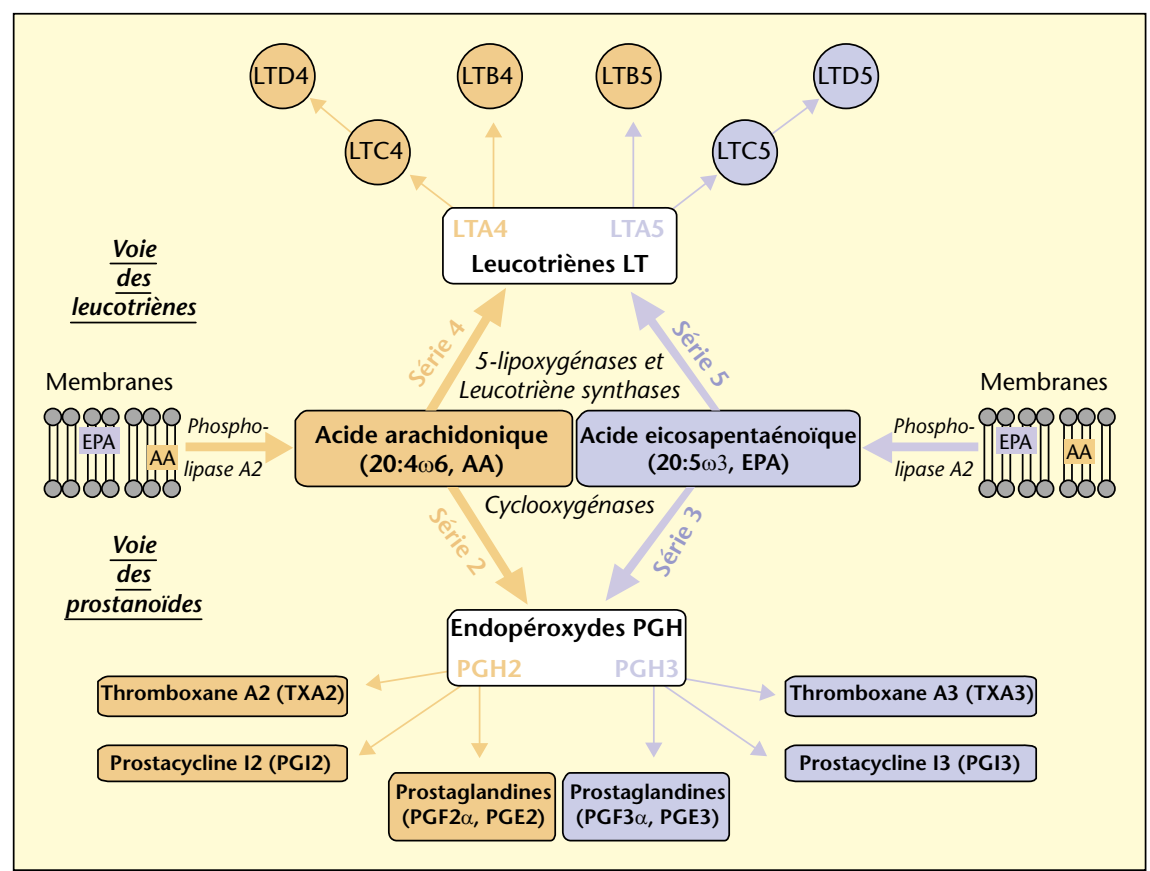

Figure 5. Voies d'oxydation enzymatique des acides arachidonique $(20: 406)$ et eicosapentaénoïque $(20: 503)$ conduisant à la synthèse des prostanoïdes (voie des cyclo-oxygénases) et des leucotriènes (voie de la 5 -lipoxygénase) (adapté d'après [21]). Dans la voie de la 5-lipoxygénase, on note la formation d'intermédiaires que sont les hydropéroxydes d'acides arachidonique et eicosapentaénoïque, dont la fonction hydropéroxyde est située en position 5 par rapport à l'extrémité carboxyle (le 5-HPETE pour le 5-hydropéroxyde d'acide eicosatétraénoïque, et le 5-HPEPE pour le 5-hydropéroxyde d'acide eicosapentaénoïque). II existe également des voies enzymatiques de 8-, 12- et 15-lipoxygénases conduisant également à la formation d'hydropéroxydes d'AGPI. Enfin, I'action séquentielle des 15 et 5-lipoxygénases sur l'acide arachidonique conduit à la synthèse de lipoxine A4. 


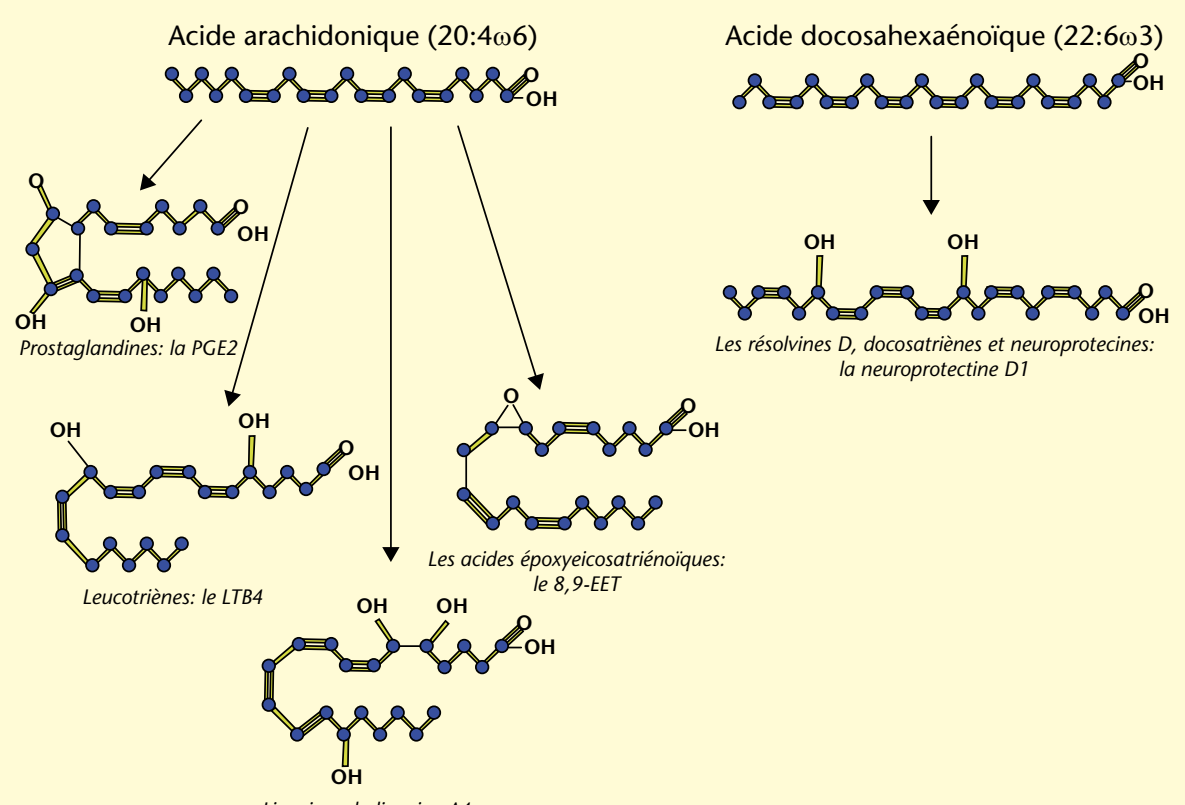

Lipoxines: Ia lipoxine A4

Figure 6. Structure des principales classes de médiateurs oxygénés générés par voie enzymatique à partir des acides arachidonique (20:406), eicosapentaénoïque (20:503) et docosahexaénoïque $(22: 6 \omega 3)$. Pour obtenir la structure des prostanoïdes (prostaglandines, prostacyclines, thromboxanes), leucotriènes et lipoxines dérivant de l'acide eicosapentaénoïque (20:503), il suffit de rajouter, dans les molécules dérivant de l'acide arachidonique (20:406), une insaturation supplémentaire en position 3 à compter du groupement méthyle terminal.

[21] (figure 5). Les leucotriènes sont principalement produits par les cellules du système immunitaire : lignées monocytes-macrophages, les éosinophiles, les basophiles et les mastocytes.

D'autres voies d'oxygénation enzymatique et d'oxydation non enzymatique des AGPI à 20C et $22 \mathrm{C}(\mathrm{DHA})$ ont été découvertes. C'est le cas de la synthèse :

- des hydroperoxydes d'AGPI en oméga 6 et oméga 3 à partir des acides arachidonique et eicosapentaénoïque par action des 5-, 8-, 12 et 15-lipoxygénases [22] ;

- des acides époxyeicotriénoïques (EET) issus de la peroxydation des AGPI à 20 atomes de carbone par la voie du cytochrome P450 [23] ; - des résolvines, docosatriènes et des neuroprotectines provenant de la conversion enzymatique des acides eicosapentaénoïque et docosahexaénoïque [24] ;

- des isoprostanes et neuroprostanes dérivant d'un processus de peroxydation nonenzymatique des acides arachidonique et docosahexaénoïque [25].

Les principaux médiateurs formés à partir des acides arachidonique et docosahexaénoïque sont représentés dans la figure 6 .

\section{Les rôles physiologiques majeurs exercés au niveau cellulaire par les acides gras polyinsaturés}

Les effets physiologiques des AGPI précurseurs et de leurs dérivés à longue chaîne mettent en jeu des mécanismes principalement impliqués dans la modulation des propriétés physicochimiques et dynamiques des membranes cellulaires, de la synthèse de médiateurs oxygénés bioactifs et de la transcription de gènes via I'activation de facteurs de transcription comme par exemple les récepteurs nucléaires sensibles aux AGPI (figure 1).

\section{Rôle structural}

Les acides linoléique, arachidonique et docosahexaénoïque sont des constituants fondamentaux des phospholipides membranaires (tableau 1). Ils modulent au sein des membranes cellulaires l'activité d'un grand nombre d'enzymes, de transporteurs, de récepteurs et de canaux ioniques impliqués dans la signalisation inter- et intracellulaire. Cet effet peut être direct, par la constitution d'un microenvironnement peu ordonné et flexible, facilitant les changements de conformation nécessaires à l'activité de protéines intrinsèques, ou indirect en induisant la ségrégation de domaines membranaires plus ordonnés enrichis en acides gras saturés, glycosphingolipides et en cholestérol (les « rafts ») auxquels sont associés des complexes protéiques actifs (impliqués par exemple dans la signalisation transmembranaire).

L'exemple de l'acide docosahexaénoïque, de par sa concentration élevée dans les membranes excitables du cerveau et de la rétine, illustre bien les propriétés physiques exercées par les AGPI au sein des membranes nerveuses [3, 26, 27]. Ainsi au niveau des cellules photoréceptrices de la rétine, la réception du photon et sa transduction en signal électrique nécessitent des changements conformationnels du photopigment rétinien (rhodopsine). Ces changements sont directement modulés par la composition phospholipidique des membranes photoréceptrices, notamment par la concentration de DHA [28] qui favorise également la ségrégation des rafts [29]. Un effet structural indirect a été également mis en évidence et implique la modulation de la biosynthèse de phospholipides membranaires régulant certains éléments des voies de signalisation comme les protéines kinases $C$ et l'apoptose (cas d'un aminophospholipide riche en DHA, la phosphatidylsérine) [30]. Enfin, certains AGPI à 14 atomes de carbone sont liés de façon cova- 
lente à la plupart des protéines membranaires impliquées dans le processus de phototransduction et pourraient ainsi faciliter leur ancrage dans la membrane des disques photorécepteurs et moduler leur activité [2].

\section{Précurseurs de médiateurs lipidiques bioactifs}

Dans l'ensemble des tissus de l'organisme, les médiateurs lipidiques jouent un rôle de messagers aux niveaux cytosolique et intercellulaire (figures 4 et 5). Ces molécules oxygénées régulent des fonctions aussi diverses que la reproduction, la physiologie cardiaque, la coagulation sanguine, I'hémostase, I'inflammation, le fonctionnement des glandes endocrines et exocrines, etc. Parmi les principales fonctions exercées par ces molécules, citons l'hémostase et le thromboxane A2 (TXA2), issu de la conversion de l'acide arachidonique au niveau des plaquettes sanguines, qui est un puissant inducteur de l'agrégation plaquettaire. La prostacycline 12 (PGI2) produit par les cellules endothéliales exerce un effet vasodilatateur visà-vis du système vasculaire et antiagrégant au niveau des plaquettes. L'équilibre entre la production de TXA2 et de PGI2 constitue un élément clé dans la régulation de l'agrégation plaquettaire et de l'hémostase. Les leucotriènes modulent l'activité du système immunitaire en contrôlant la différenciation et les fonctions des lymphocytes $T$, des mastocytes, des macrophages, etc. La PGE2 exerce également de multiples effets pro-inflammatoires [31]. Ces médiateurs sont également impliqués dans les processus d'activation neuronale et d'inflammation au niveau du système nerveux central [32]. La PGE2 a été ainsi identifiée comme étant un régulateur majeur de l'activité et de la plasticité synaptiques. Les mécanismes d'action des eicosanoïdes mobilisent des récepteurs membranaires couplés à des protéines $G$, conduisant à l'augmentation de la concentration intracellulaire d'AMP cyclique et à l'activation de voies de signalisation cellulaire (cascade de la protéine kinase $A$, mobilisation du calcium via l'activation de la phospholipase $C$, etc.). Les effets des médiateurs dérivés de l'acide arachidonique mettent également en œuvre l'activation de facteurs nucléaires de transcription tels que les récepteurs aux proliférateurs de peroxysomes (PPAR) comme nous le détaillerons dans le paragraphe suivant.

Les dérivés endopéroxydés du DHA, neuroprotectine D1 et neuroprostanes, exercent également des propriétés spécifiques : la neuroprotectine D1 exerce notamment des effets antiinflammatoires en inhibant l'infiltration des leucocytes, et s'oppose au processus d'apoptose en limitant l'expression de facteurs pro-apoptotiques induits par un stress oxydant (ischémie cérébrale). Les neuroprostanes exercent également des effets neuroprotecteurs.

\section{Rôle modulateur de la transcription génique}

Les acides gras et leurs métabolites régulent l'expression d'un grand nombre de gènes par I'intermédiaire de multiples facteurs de transcription, parmi lesquels les plus importants sont les récepteurs aux proliférateurs de peroxysomes (PPAR pour peroxisome proliferator-activated receptors), la protéine de liaison à l'élément de régulation des stérols (SREBP-1c pour sterol regulatory element binding protein-1c), les facteurs nucléaires hépatiques (HNF4 pour hepatic nuclear factor 4), le récepteur aux rétinoïdes (RXRa pour retinoid $X$ receptor) et le récepteur hépatique $X$ (LXRa pour liver $X$ receptor). Le dysfonctionnement de ces facteurs de régulation est déterminant dans le processus de résistance à l'insuline et des pathologies qui lui sont associées (syndrome métabolique). La régulation génique s'effectue au niveau des noyaux des cellules par interaction directe (liaison) des acides gras avec ces récepteurs nucléaires (PPAR, HNF4, RXR $\alpha$, $L X R \alpha$ ), ou de façon indirecte en inhibant la transcription du récepteur lui-même (SREBP1c). Le foie et le tissu adipeux sont particulièrement concernés par ces processus de régulation, qui impliquent notamment les AGPI. En effet, il a été démontré que les AGPI stimulent la voie catabolique en activant la transcription de protéines de transport des acides gras et d'enzymes de la $\beta$-oxydation (mitochondriale et peroxysomale). En outre, les AGPI réduisent l'activité lipogénique du tissu hépatique en réprimant la transcription de facteurs et d'enzymes lipogéniques (figure 7) [33, 34]. Ces processus de régulation sont à l'origine des propriétés hypolipémiantes, partagées par cer-

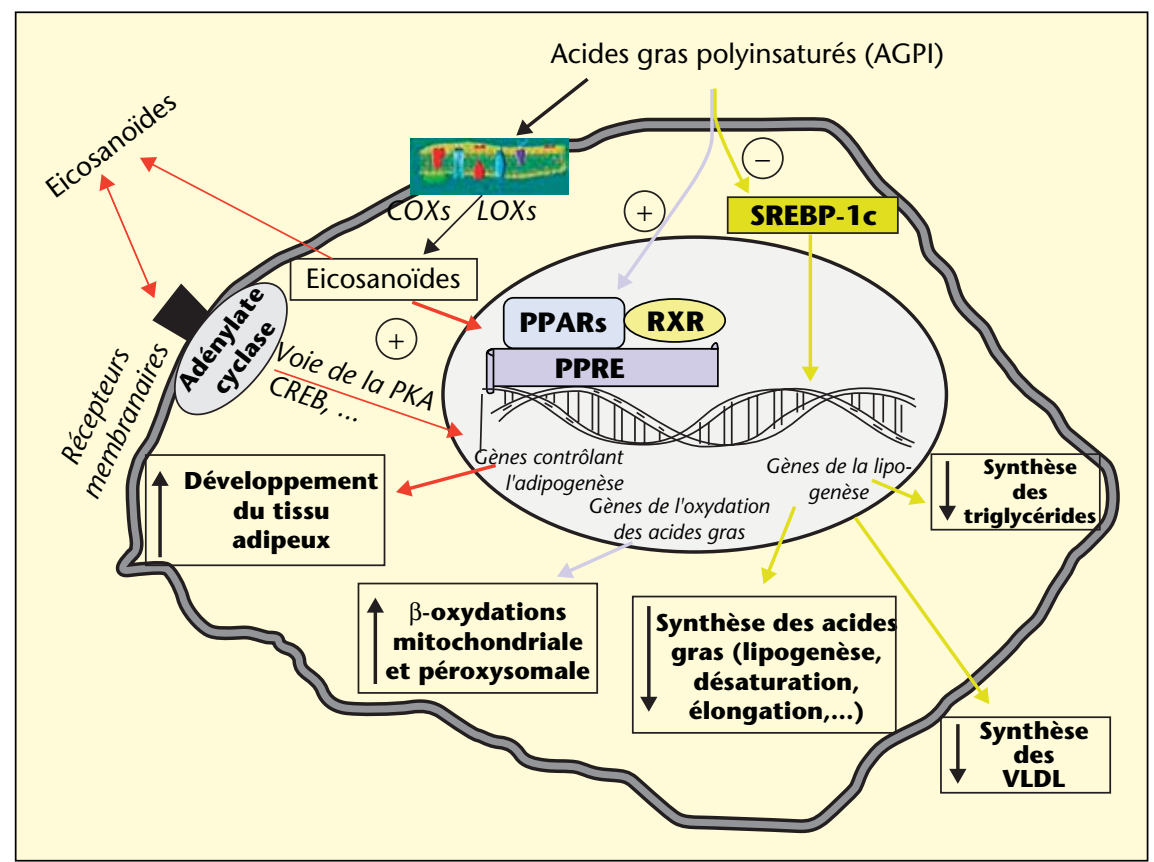

Figure 7. Représentation schématique des effets des acides gras polyinsaturés (AGPI) sur la transcription de gènes du métabolisme lipidique au niveau des cellules hépatiques et de l'adipocyte (adaptée selon [33, 36]). Au niveau du foie, les AGPI en oméga 6 et oméga 3 stimulent le catabolisme des acides gras ( $\beta$-oxydation et voie de PPAR $\alpha$ ) et inhibent leur anabolisme (synthèse des acides gras, des triglycérides et des VLDL et voie de SREBP-1C); pour leur part, les oméga 3 inhibent plus fortement la synthèse des triglycérides et des VLDL que les oméga 6, expliquant les propriétés hypotriglycéridémiantes de cette famille d'AGPI. Au niveau du tissu adipeux, les AGPI oméga 6 stimulent l'expression des gènes de la différenciation adipocytaire via la synthèse de médiateurs lipidiques et l'activation de voies spécifiques (prostacycline 12, voie de la protéine kinase A et du récepteur nucléaire PPARס; dérivés de la lipoxygénation de l'acide arachidonique et activation de PPARy). Pour leur part, les AGPI oméga 3 auraient des potentialités adipogéniques moindres que les oméga 6 (inhibition de la production de prostacycline 12 par exemple).

COX, cyclo-oxygénases; CREB, élément de liaison protéique répondant au CAMP (CAMP-responsive element binding protein ; LOX, lipoxygénases; PKA, protéine kinase A; PPAR, récepteurs aux proliférateurs de péroxysomes (peroxisome proliferator-activated receptors); PPRE, élément de réponse auX PPAR (PPAR response element); $R X R$, récepteur aux rétinoides (retinoid $X$ receptor); SREBP-1C, protéine de liaison à l'élément de régulation des stérols (sterol regulatory element binding protein-1 c); VLDL, very low density lipoprotein. 
tains AGPI, des ligands pharmacologiques des PPAR (médicaments provoquant la prolifération des péroxysomes hépatiques chez les rongeurs). Ces propriétés hypolipémiantes se traduisent notamment par la diminution de la synthèse et de la mise en circulation des lipoprotéines les plus riches en triglycérides, les VLDL. Les AGPI régulent également l'expression d'un grand nombre de gènes codant pour des protéines contrôlant le développement du tissu adipeux et le métabolisme des sucres.

De façon générale, les PPAR jouent un rôle clé dans la régulation du métabolisme énergétique et sont également impliqués dans le contrôle du processus inflammatoire [35]. Les isoformes PPAR $\alpha$ et PPAR $\gamma$ sont activés directement par les AGPI et par leurs dérivés oxygénés (prostanoïdes, leucotriènes), induisant l'association avec le récepteur aux rétinoïdes (RXR) qui se lie à l'ADN sur une séquence spécifique (PPRE) du promoteur des gènes cibles (figure 7). La nature de l'isoforme oriente la réponse métabolique des tissus. Ainsi, PPAR $\alpha$ est exprimé au niveau du foie, du tissu adipeux brun (et du muscle) et active in situ le catabolisme des acides gras; PPAR $y$ est principalement exprimé dans le tissu adipeux blanc dont il contrôle la différenciation et le développement [36]. Au niveau du foie, les AGPI, via I'activation de PPAR $\alpha$, induisent la transcription de multiples enzymes régulant les voies de $\beta$-oxydation mitochondriale et peroxysomale et de cétogenèse des acides gras, et diminuent la synthèse de malonyl-CoA qui est un métabolite inhibiteur majeur de ces voies [33, 34] (figure 7). Au niveau du tissu adipeux, le type de régulation mis en jeu est plus complexe ; il implique à la fois les AGPI et leurs dérivés oxygénés, une autre isoforme des PPAR (PPAR $\delta$ ) et deux étapes de l'adipogenèse, la différenciation et l'hyperplasie [36]. L'activation de PPAR $\delta$ intervient dans la régulation du processus de différenciation en préadipocytes et fait intervenir les prostacyclines et également une boucle autocrine de régulation via des récepteurs membranaires spécifiques, tandis que celle de PPAR $\gamma$ conduit à la maturation des adipocytes immatures (activation des enzymes de la lipogenèse) (figure 7).

L'inactivation de SREBP-1c par les AGPI au niveau hépatique conduit à l'inhibition de la synthèse de plusieurs protéines enzymatiques contrôlant les voies de la lipogenèse de novo des acides gras (acétylCoA synthase, acétylCoA carboxylase, acide gras synthase), de bioconversion des AGPI $(\Delta 9$-, $\Delta 6$ - et $\Delta 5$-désaturases, élongases) et de synthèse des triglycérides (diacylglycérol acyltransférase, etc.) (figure 7). SREBP-1c est une protéine qui, sous la forme inactive, est localisée dans le réticulum endoplasmique. Son activation par clivage protéolytique lui permet de se lier au niveau de
I'ADN nucléaire sur l'élément de réponse aux stéroïdes (SRE) et ainsi d'activer la transcription des protéines lipogéniques. Les AGPI interagiraient directement sur la transcription de SREBP ou sur son clivage post-traductionnel.

La voie des récepteurs nucléaires aux AGPI est également impliquée dans la régulation de la transcription de la lipoprotéine lipase et d'apolipoprotéines des lipoprotéines HDL et VLDL (voie de SREBP-1c pour cette dernière lipoprotéine). L'expression de gènes impliqués dans le métabolisme cérébral des acides gras et dans la neurotransmission (libération de neurotransmetteur, canaux ioniques, connexions, etc.) seraient également régulés par les AGPI selon des mécanismes moléculaires qui ne sont pas encore élucidés; ils mettent probablement en jeu la voie des PPAR et du RXR [3].

\section{Impacts physiologique et cellulaire des AGPI oméga 6 et oméga 3}

L'apport alimentaire en AGPI des familles oméga 6 et oméga 3 est le principal déterminant du niveau de biosynthèse et d'incorporation des AGPI dans les phospholipides des membranes cellulaires. Les AGPI précurseurs (acides linoléique et $\alpha$-linolénique) entrent tout d'abord en compétition pour les enzymes impliquées dans la biosynthèse des AGPI à longue chaîne, en particulier pour les désaturases.
En conséquence, un apport alimentaire excessif d'acide linoléique (oméga 6) inhibe par compétition la bioconversion de l'acide a-linolénique (oméga 3 ) en ses dérivés supérieurs (acides eicosapentaénoïque et docosahexaénoïque) ainsi que leur incorporation tissulaire, et ce d'autant plus si l'apport alimentaire direct en ces dérivés est faible (figure 8). Ce déséquilibre provoque l'augmentation de l'incorporation de l'acide arachidonique dans les phospholipides membranaires, au détriment des dérivés supérieurs en oméga 3. Ce remplacement s'effectue dans l'ensemble des membranes tissulaires (cellules circulantes, foie, etc.), et en particulier dans le tissu nerveux pendant la période périnatale de développement cérébral. Dans les membranes cérébrales, la diminution de la teneur en acide docosahexaénoïque s'accompagne de l'incorporation compensatrice de son analogue métabolique de la série oméga 6, l'acide docosapentaénoïque $(22: 5 \omega 6)$, dont la teneur élevée est un critère biochimique de déficit d'apport alimentaire en oméga 3. On recommande pour cette raison un rapport linoléique/ $\alpha$-linolénique dans I'alimentation proche de 5, ainsi qu'un apport direct sous la forme d'acide docosahexaénoïque afin de satisfaire la totalité des besoins de I'organisme [19]. Or, on constate dans un grand nombre de pays industrialisés un excès d'apport alimentaire en oméga 6 par rapport aux oméga 3 , à l'origine d'un déséquilibre $d^{\prime}$ incorporation dans les membranes cellulaires des dérivés à longue chaîne [36, 37].

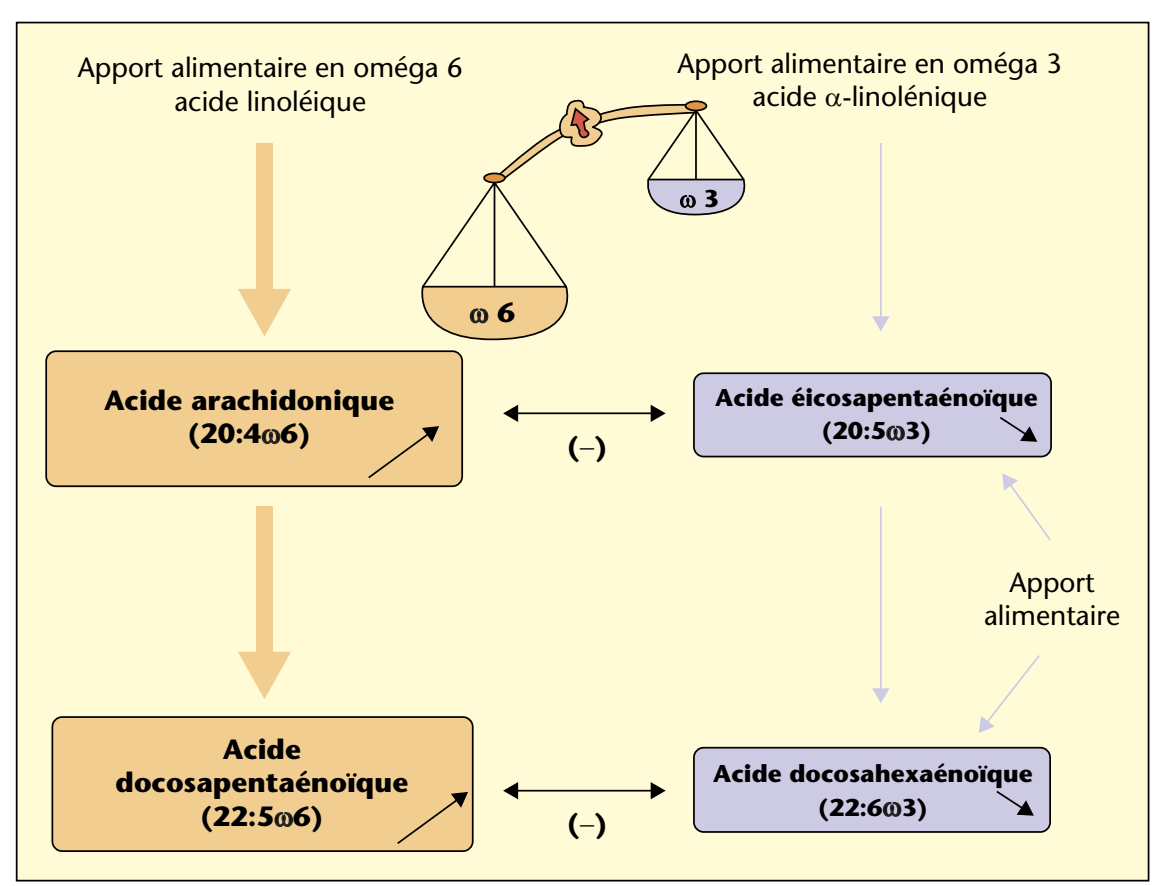

Figure 8. Conséquences d'un apport alimentaire déséquilibré en oméga 6/oméga 3 sur la biosynthèse des AGPI à longue chaîne. 
Déséquilibre d'apport alimentaire en oméga 6 et oméga 3 et physiologie nerveuse Conséquence neurosensorielle chez I'enfant allaité artificiellement

Expérimentalement chez l'animal (rongeur, singe) au cours de la période de développement périnatal (gestation-lactation), il a été largement démontré que la diminution de la teneur membranaire en DHA s'accompagne d'une réduction des capacités d'apprentissage et de discrimination visuelle (acuité visuelle, amplitude de l'onde $b$ de l'électrorétinogramme). Chez le nouveau-né humain (prématuré et né à terme), il a été mis en évidence que la consommation de laits infantiles pauvres en oméga 3, formulés avec de l'huile de maïs, conduit rapidement à la diminution de la concentration en DHA dans les membranes érythrocytaires et cérébrales, et à un retard de maturation des fonctions visuelles (diminution de la sensibilité des cellules photoréceptrices mesurée par électrorétinographie et diminution de l'acuité visuelle évaluée par un réflexe visuel), comparativement à des enfants allaités au sein pris comme référence nutritionnelle et fonctionnelle [12]. Un apport équilibré en acide $\alpha$-linolénique permet de restaurer ces fonctions. Cependant, cette réversion est partielle car les paramètres fonctionnels restent inférieurs à ceux du groupe de référence. Ces différences dues au type d'allaitement sont liées à la présence d'acide docosahexaénoïque dans le lait maternel qui est rapidement incorporé dans les membranes cérébrales. Les études de supplémentation en DHA conduites chez l'enfant indiquent que le statut en oméga 3 peut être facilement réhaussé, I'acuité visuelle n'étant améliorée que dans les cas où elle était significativement inférieure à celle du groupe de référence.

\section{Déséquilibre d'apport alimentaire en oméga 6 et oméga 3 - \\ Conséquences sur les phénomènes d'agrégation plaquettaire, inflammatoire et immunitaire}

Les médiateurs dérivés de l'acide arachidonique (prostaglandines, prostacyclines, thromboxanes, leucotriènes, lipoxines, etc.) sont synthétisés en plus grande quantité que ceux issus de la famille oméga 3 (figure 9, partie A). De part leur propriétés fonctionnelles (activité proagrégante du thromboxane $\mathrm{A} 2$ et activité inflammatoire du leucotriène B4 par exemple) et leur grande efficacité biologique à faibles concentrations, ils vont favoriser les processus de thrombose, d'allergie et d'inflammation [21]. L'ingestion d'un régime équilibré en AGPI ou riche en oméga 3 à longue chaîne, contenus
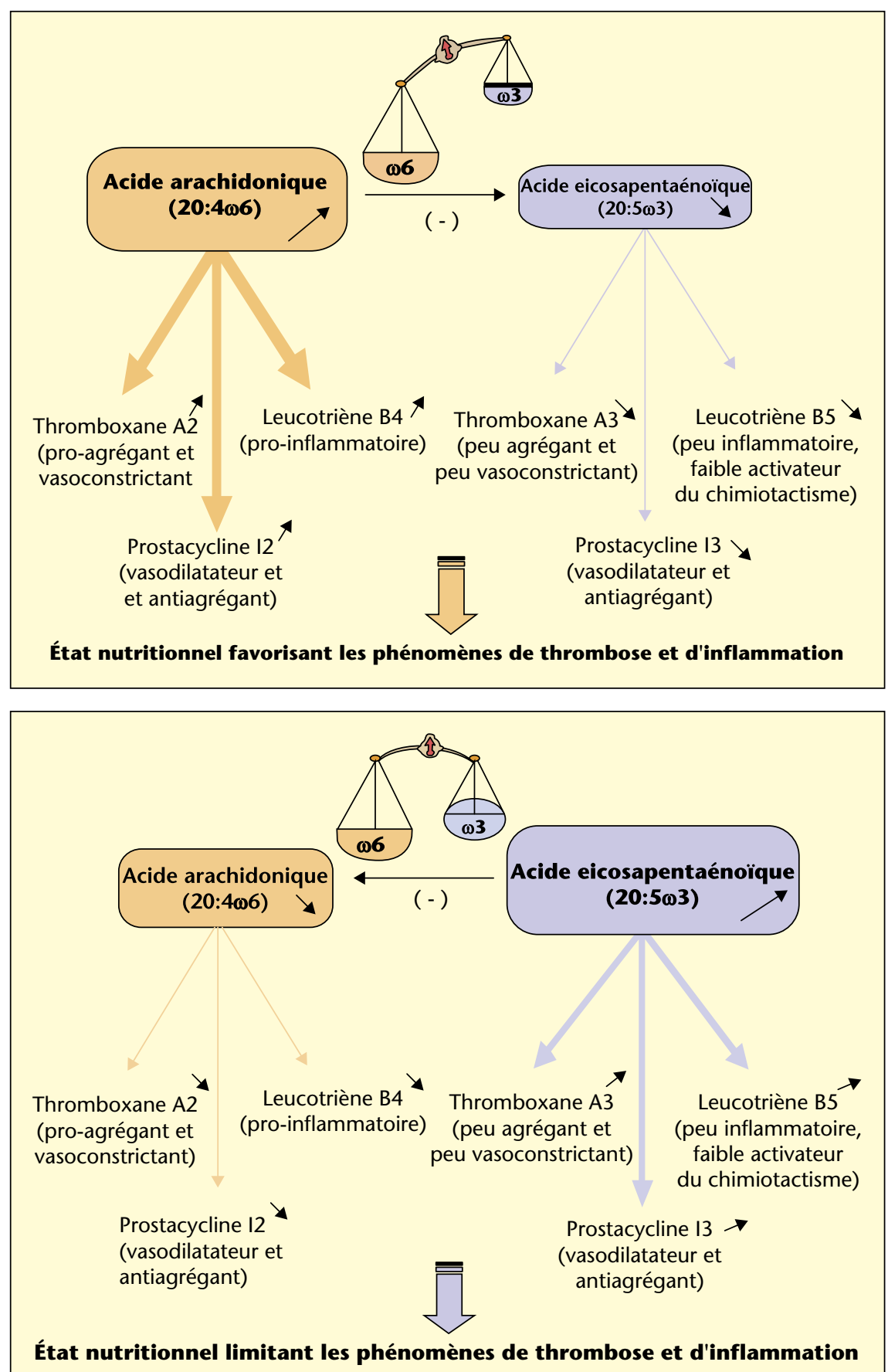

Figure 9. Apport alimentaire en oméga 6 et oméga 3 et synthèse des principaux médiateurs oxygénés.

par exemple dans les poissons gras (acide eicosapentaénoïque), a des effets bénéfiques en réduisant par inhibition compétitive l'incorporation de l'acide arachidonique dans les membranes cellulaires (moindre biodisponibilité) et en limitant la conversion de ce dernier en médiateurs actifs. Certains des médiateurs de l'acide eicosapentaénoïque exercent en effet des propriétés antagonistes à ceux issus de I'acide arachidonique, ou sont biologiquement moins actifs : ils réduisent l'agrégation plaquet- taire (le thromboxane $\mathrm{A} 3$ présente par exemple une faible activité proagrégante et vasoconstrictive) et ils atténuent les réactions inflammatoires (le leucotriène B5 possède de faibles activités pro-inflammatoire et de chimiotactisme) (figure 9, partie B) [21]. Ces effets bénéfiques sont également liés au fait que la synthèse des médiateurs lipidiques issus de l'acide eicosapentaénoïque est moindre que celle des dérivés de l'acide arachidonique, limitant ainsi la production globale de certains eicosanoïdes 
dérivant des deux séries, oméga 6 et oméga 3 (exemple des prostacyclines).

Ainsi, c'est par la balance d'incorporation membranaire des oméga 6 et des oméga 3 et, par voie de conséquence, de la synthèse de leurs médiateurs respectifs, que l'apport alimentaire en AGPI peut influer sur l'incidence des maladies cardiovasculaires (incluant l'athérosclérose, la maladie des coronaires et les maladies cérébrovasculaires) et inflammatoires. La particularité des propriétés bénéfiques des oméga 3 en nutrition humaine est apparue il y a maintenant une trentaine d'années, à partir d'observations épidémiologiques comparatives entre les Ésquimaux groenlandais et les Danois [38]. Ces observations relevaient une moindre prévalence des maladies cardiovasculaires et inflammatoires dans la population inuit, dans laquelle la consommation de graisses animales se fait exclusivement par l'apport d'animaux marins, très riches en acides gras oméga 3 à longue chaîne (acides eicosapentaénoïque et docosahexaénoïque). Les études épidémiologiques d'observation qui ont été publiées depuis lors ont confirmé l'intérêt de cette famille d'AGPI de ce point de vue, rapportant une corrélation négative entre la consommation de poisson et/ou d'oméga 3 (précurseur et dérivés à longue chaîne) et l'incidence des maladies cardiovasculaires, que la plupart des études d'intervention secondaires ont confirmé [38]. En plus de la modulation de la production des eicosanoïdes, d'autres mécanismes rendent compte des propriétés bénéfiques des oméga 3 sur le plan cardiovasculaire, impliquant notamment l'inhibition de la production de cytokines (interleukines 1 et 6 par exemple qui régulent l'agrégation plaquettaire et la fixation des molécules d'adhésion à I'endothélium vasculaire), du fibrinogène, du PAF (Platelet Activating Factor), etc. [21]. L'acide docosahexaénoïque pourrait également jouer un rôle cardioprotecteur par ses propriétés anti-hypertensive et antiarythmique [39].

\section{Acides gras oméga 6 et oméga 3 et transcription génique Régulation du métabolisme lipidique hépatique et de l'adipogenèse}

D'une façon générale les AGPI contrôlent le métabolisme des acides gras en activant la voie catabolique et en réprimant la voie anabolique. Nous avons vu que le métabolisme lipidique, mettant en jeu les voies de lipogenèse de novo des acides gras, de désaturation-élongation des AGPI, de synthèse des triglycérides et de sécrétion des VLDL, et de $\beta$-oxydation et de cétogenèse des acides gras, est régulée par les AGPI au niveau du foie via la voie des récepteurs nucléaires (PPAR $\alpha$ et SREBP-1C) (figure 7). II a été cependant montré que les oméga 3 répri- ment plus efficacement que les oméga 6 les voies de synthèse des triglycérides et d'assemblage des VLDL, réduisant ainsi la sécrétion de ces lipoprotéines dans la circulation sanguine et le risque d'hypertriglycéridémie qu'elles représentent $[33,34]$. Cette propriété des oméga 3 a été démontrée par des essais chez I'homme, montrant que la consommation d'oméga 3 à longue chaîne entraîne une baisse notable de la triglycéridémie, en particulier chez les sujets hypertriglycéridémiques [38]. Les mécanismes mis en jeu ne sont pas encore connus avec précision et impliqueraient une diminution de la quantité intracellulaire de SREBP-1c par régulation transcriptionnelle et post-transcriptionnelle (clivage protéolytique, turn-over).

Concernant le développement de l'obésité et ses facteurs de risque, on sait maintenant que la nature des acides gras de l'alimentation, à travers l'équilibre entre oméga 6 et oméga 3 , est susceptible de moduler le développement du tissu adipeux pendant la période périnatale. Cette période particulièrement sensible aux facteurs environnementaux, pendant laquelle se produit un accroissement hyperplasique $\mathrm{du}$ tissu adipeux, est physiologiquement critique. En effet, les études conduites in vivo chez la souris et in vitro sur adipocytes isolés ont démontré que les oméga 6 , à travers leur principal représentant à longue chaîne, l'acide arachidonique, sont de puissants activateurs de la différenciation adipocytaire, contrairement aux oméga 3 qui contrecarrent les effets proadipogéniques des oméga 6 [37]. L'acide arachidonique activerait, directement ou indirectement par ses dérivés oxygénés, le processus $d^{\prime}$ adipogenèse au cours des étapes de différenciation de l'adipoblaste en préadipocyte puis du préadipocyte en adipocyte, cellule mature constitutive du tissu adipeux blanc. La première étape de différenciation, qui favorise l'expression de gènes de la différenciation préadipocytaire, met notamment en jeu la prostacycline I 2 via l'activation de la protéine kinase à par la voie de son récepteur membranaire, et I'activation de PPAR $\delta$ (figure 7). La seconde étape de différenciation implique également les produits de la lipoxygénation de l'acide arachidonique et I'activation de PPAR $\gamma$ qui stimule par contre coup l'expression des gènes des enzymes de la lipogenèse. En limitant la production de prostacycline 12 , les acides eicosapentaénoïque et docosahexaénoïque auraient des potentialités adipogéniques bien moindres que celles des oméga 6 . Ces résultats peuvent être mis en parallèle avec l'augmentation de la prévalence de l'obésité infantile, notamment aux Etats-Unis où des changements qualitatifs importants des apports alimentaires en AGPI se sont produits au cours des dernières décennies, se traduisant notam- ment par un déséquilibre entre oméga 6 et oméga 3 spécifiquement lié à l'augmentation de la consommation d'acides linoléique et arachidonique [37]. On constate un accroissement progressif de la quantité d'acide linoléique consommé depuis les années 50 , passant de moins de $4 \%$ des calories totales ingérées à plus de $8 \%$ à partir des années 90 . Cette évolution se reflète dans celle de la composition du lait maternel, dont la teneur en acide linoléique s'est également accrue au cours de cette période, avoisinant les 6-7 \% des acides gras totaux en 1950 pour atteindre la valeur de $15-16 \%$ dans les années $80-90$, soit une teneur dans le lait correspondant à près de deux fois l'apport recommandé pour le nouveau-né. Pendant la même période, la teneur en acide $\alpha$-linolénique est restée stable, se traduisant par l'accroissement progressif du rapport oméga 6/oméga 3, lequel peut aujourd'hui atteindre dans le lait maternel des valeurs supérieures à 20 alors que le niveau recommandé est de 5 . Ces données suggèrent que la nature des AGPI ingérés pourrait favoriser le développement précoce du tissu adipeux, et donc le risque d'obésité dès les premières années de la vie.

\section{Conclusion}

Les AGPI en oméga 6 et oméga 3 exercent de multiples fonctions physiologiques au niveau de notre organisme comme constituants des membranes cellulaires, précurseurs de médiateurs lipidiques bioactifs et régulateurs de facteurs de transcription orientant notamment le métabolisme lipidique. Dans un grand nombre de pays industrialisés, l'absence de diversification est vraisemblablement à l'origine d'une alimentation déséquilibrée en AGPI (précurseurs et dérivés à longue chaîne) car excessive en oméga 6 et relativement déficitaire en oméga 3. Cette alimentation est préjudiciable à la synthèse des AGPI à longue chaîne en oméga 3 (EPA et DHA) et à leur incorporation dans les membranes cellulaires, contribuant par là même à favoriser certaines pathologies telles que les maladies cardiovasculaires, les maladies auto-immunes et inflammatoires, le diabète et certaines neuropathologies [38]. Ce déséquilibre s'est progressivement installé depuis ces 40 dernières années, et l'augmentation concomitante de la prévalence de l'obésité (notamment juvénile) suggère qu'il a favorisé l'émergence de cette pathologie [37]. Si c'est principalement l'incorporation d'acide docosahexaénoïque au niveau des membranes cérébrales qui revêt une importance manifeste pour le développement neurosensoriel du nouveau-né, c'est davantage l'équilibre du niveau d'incorporation tissulaire entre acide arachidonique et oméga 3 (EPA et DHA) qui est l'un des facteurs 
favorisant l'émergence de certaines situations pathologiques. L'acide arachidonique n'a pas en tant que tel d'effet défavorable sur la santé car il est un constituant ubiquitaire majeur des membranes cellulaires et à la base d'un grand nombre de processus physiologiques [40]. Cependant dans un contexte pathologique, l'activation de la production d'eicosanoïdes à partir de l'acide arachidonique devient alors un processus chronique à l'origine de perturbations physiologiques, voire pathologiques, processus qui peut être en partie contrôlé par la présence en quantité équilibrée d'acides gras en oméga 3.

\section{RÉFÉRENCES}

1. MALVY D, PREZIOSIP, GALAN P, et al. La consommation de lipides en France : contribution à l'équilibre nutritionnel (données préliminaires de l'étude Su. Vi. Max). OCL 1999; 6 : 21-5.

2. DURAND G, GUESNET P, CHALON S, ALESSANDRI JM, RIZKALLA S, LEBRANCHU Y. Importance nutritionnelle des acides gras polyinsaturés. In : Roberfroid M, ed. Aliments Fonctionnels. Paris : Editions Tec \& Doc-Lavoisier, 2002 : 193-219.

3. ALESSANDRI JM, GUESNET P, VANCASSEL $S$. Polyunsaturated fatty acids in the central nervous system : evolution of concepts and nutritional implications throughout life. Reprod Nutr Dev 2004 ; 44 : 509-38.

4. GUESNET P, ALESSANDRI JM, VANCASSEL $S$, ZAMARIA N. Analysis of the 2nd symposium "Anomalies of fatty acids, ageing and degenerating pathologies". Reprod Nutr Dev 2004 ; 44 : 263-71.

5. HOLMAN RT. Biological activities of polyunsaturated fatty acids. Prog Chem fats lipids 1970 ; IX : 607-82.

6. HOLMAN RT. The slow discovery of the importance of omega 3 essential fatty acids in human health. / Nutr $1998 ; 128$ : 427S-433S.

7. SODERHJELM L, WIESE H, HOLMAN R. The role of polyunsaturated acids in human nutrition and metabolism. Prog Chem fats lipids 1970 ; IX : 555-85.

8. TINOCO J. Dietary requirements and functions of alpha-linolenic acid in animals. Prog Lipid Res $1982 ; 21: 1-45$.

9. BANG H, DYERBERG ], NIELSEN A. Plasma lipid and lipoprotein pattern in Greenlandic Westcoast Eskimos. Lancet 1971 ; i : 1143-6.

10. LAURITZEN L, HANSEN HS, JORGENSEN MH, MICHAELSEN KF. The essentiality of long chain $\mathrm{n}-3$ fatty acids in relation to development and function of the brain and retina. Prog Lipid Res $2001 ; 40: 1-94$.
11. HOLMAN RT, JOHNSON SB, HATCH TF. A case of human linolenic acid deficiency involving neurological abnormalities. Am / Clin Nutr $1982 ; 35: 617-23$

12. GUESNET P, ALESSANDRI JM. Acides gras polyinsaturés du lait et développement du système nerveux central du nouveau-né. Cah Nutr Diét $1995 ; 30: 109-11$.

13. BERGSTRÖM S. Prostaglandins from bedside observation to a family of drugs. Prog Lipid Res $1981 ; 20: 7-12$.

14. SAMUELSSON B. Leukotrienes : A novel group of compounds including SRS-A. Prog Lipid Res $1981 ; 20: 23-30$.

15. CHARDIGNY JM, MALPUECH-BRUGERE C, SEBEDIO JL. CLAs, nature, origin and some metabolic aspects. OCL $2005 ; 12$.

16. MARTIN JC, VALEILLE K. Conjugated linoleic acids: all the same or to everyone its own function? Reprod Nutr Dev 2002 ; 42 : 525-36.

17. WOLFF R. New tools to explore lipid metabolism. Inform 1997; 8 : 116-9.

18. SPRECHER H. Metabolism of highly unsaturated n-3 and n-6 fatty acids. Biochim Biophys Acto $2000 ; 1486: 219-31$.

19. BURDGE G. $\alpha$-Linolenic acid metabolism in men and women: nutritional and biological implications. Curr Opin Clin Nutr Metab Care $2004 ; 7$ : 137-44.

20. CUNNANE SC. Problems with essential fatty acids : time for a new paradigm? Prog Lipid Res $2003 ; 42: 544-68$

21. SIMOPOULOS AP. The importance of the ratio of omega-6/omega-3 essential fatty acids. Biomed Pharmacother 2002 ; 56 : 365-79.

22. YAMAMOTO S. Mammalian lipoxygenases: molecular structures and functions. Biochim Biophys Acta $1992 ; 1128$ : 117-31.

23. SPECTOR AA, FANG $X$, SNYDER GD, WEINTRAUB NL. Epoxyeicosatrienoic acids (EETs) : metabolism and biochemical function. Prog Lipid Res 2004 ; 43 : 55-90.

24. SERHAN CN, ARITAM, HONG S, GOTLINGER K. Resolvins, docosatrienes, and neuroprotectins, novel omega-3-derived mediators, and their endogenous aspirintriggered epimers. Lipids $2004 ; 39$ : 1125-32.

25. ROBERTS LI, FESSEL JP, DAVIES SS. The biochemistry of the isoprostane, neuroprostane, and isofuran Pathways of lipid peroxidation. Brain Pathol $2005 ; 15$ : 143-8.

26. ALESSANDRI JM, GUESNET P. Multiple facets of membrane lipids and the diversity of their action mode with special emphasis on the central nervous system. Reprod Nutr Dev 2005 ; $45: 529-33$.

27. STILLWELL W, SHAIKH S, ZEROUGA M, SIDDIQUI R, WASSALL S. Docosahexaenoic acid affects cell signaling by altering lipid rafts. Reprod Nutr Dev 2005 ; 45 : 559-79.
28. NIU SL, MITCHELL DC, LIM SY, ET AL. Reduced $G$ protein-coupled signaling efficiency in retinal rod outer segments in response to $\mathrm{n}-3$ fatty acid deficiency. J Biol Chem 2004 ; 279 : 31098 104.

29. SHAIKH SR, DUMAUAL AC, CASTILLO A, et al. Oleic and docosahexaenoic acid differentially phase separate from lipid raft molecules: a comparative NMR, DSC, AFM, and detergent extraction study. Biophys / $2004 ; 87$ : 1752-66.

30. KIM HY, BIGELOW J, KEVALA JH. Substrate preference in phosphatidylserine biosynthesis for docosahexaenoic acid containing species. Biochemistry $2004 ; 43$ : 1030-6.

31. BOYCE JA. Eicosanoid mediators of mast cells : receptors, regulation of synthesis, and pathobiologic implications. Chem Immunol Allergy $2005 ; 87: 59-79 ;(2005)$.

32. BAZAN NG. Lipid signaling in neural plasticity, brain repair, and neuroprotection. Mol Neurobiol 2005 ; 32 : 89-103.

33. CLARKE SD. Polyunsaturated fatty acid regulation of gene transcription : a molecular mechanism to improve the metabolic syndrome. 1 Nutr $2001 ; 131: 1129-32$

34. JUMP DB, BOTOLIN D, WANG Y, XU J, CHRISTIAN B, DEMEURE O. Fatty Acid regulation of hepatic gene transcription. J Nutr 2005 ; $135: 2503-6$.

35. STAELS B, FRUCHART J. Therapeutic roles of peroxisome proliferator-activated receptor agonists. Diabetes $2005 ; 54$ : 2460-70.

36. AILHAUD G, GUESNET P. Fatty acid composition of fats is an early determinant of chidhood obesity : a short review and an opinion. Obes Rev $2004 ; 5: 21-6$.

37. AILHAUD $G$, MASSIERA F, WEILL $P$, LEGRAND P, ALESSANDRI, GUESNET P. Temporal changes in dietary fats : role of $n-6$ polyunsaturated acids in excessive adipose tissue development and relationship to obesity. Prog Lipid Res 2006 ; (sous presse).

38. ASTORG $P$, GUESNET $P$, ALESSANDRI JM, GALAN P, LAVIALLE M. Acides gras polyinsaturés en oméga- 3 et santé : aperçu des connaissances actuelles. Sci Aliments 2006; (sous presse).

39. GRYNBERG A. Hypertension prevention : from nutrients to (fortified) foods to dietary patterns. Focus on fatty acids. I Hum Hypertens 2005; $19:$ S25-S33.

40. CRAWFORD MA. Commentary on the workshop statement. Essentiality of and recommended dietary intakes for Omega-6 and Omega-3 fatty acids. Prostaglandins Leukot Essent Fatty Acids $2000 ; 63: 131-4$. 